\section{Adverse events and complications associated with intravitreal injection of anti-VEGF agents: a review of literature}

\begin{abstract}
Intravitreal injection of anti-vascular endothelial growth factor (VEGF) agents is increasingly used for the treatment of a wide variety of retinal diseases, including age-related macular degeneration, diabetic retinopathy and retinal vascular occlusions, and retinopathy of prematurity. Despite encouraging results in halting the disease and improving the vision, intravitreal injection of anti-VEGF agents may be associated with systemic adverse events and devastating ocular complications. In this review, we provide an overview of safety data for intravitreal injection of common anti-VEGF agents.
\end{abstract}

Eye (2013) 27, 787-794; doi:10.1038/eye.2013.107; published online 31 May 2013

Keywords: intravitreal injection; anti-vascular endothelial growth factor; bevacizumab; ranibizumab; aflibercept; safety

\section{Introduction}

Intravitreal injection of anti-vascular endothelial growth factor (anti-VEGF) agents have revolutionized the treatment of common retinal diseases, including neovascular age-related macular degeneration (AMD), ${ }^{1}$ diabetic retinopathy, $^{2}$ and retinal vein occlusions (RVOs). ${ }^{3}$ Moreover, promising results were reported with intravitreal injection of anti-VEGF agents for other ocular diseases, such as neovascular glaucoma, ${ }^{4}$ retinopathy of prematurity (ROP), ${ }^{5}$ and intraocular tumors. ${ }^{6}$

Currently, several anti-VEGF drugs, including pegaptanib, ranibizumab, bevacizumab, and aflibercept, are available. Although
K Ghasemi Falavarjani and QD Nguyen² well-designed randomized clinical trials have shown the efficacy of these agents in visual improvement in various retinal diseases, each intravitreal injection poses the risk of postinjection- and drug-class-associated adverse events. ${ }^{7-9}$ The repeated and long-term injections that are commonly needed may increase the chance of ocular and systemic complications. In this article, we briefly review the adverse events and common complications following intravitreal injection of anti-VEGF agents in clinical practice.

\section{Materials and methods}

One of the authors (KGF) completed a systematic search in Pubmed database without data restriction for articles related to intravitreal anti-VEGF injections. From January 2005 to November 2012, articles with the following keywords were recruited: anti-vascular endothelial growth factor, pegaptanib, bevacizumab, ranibizumab, and aflibercept. All articles were carefully reviewed to select those that reported complications and adverse events in intravitreal anti-VEGF injections.

\section{Adverse events following intravitreal anti-VEGF injections unrelated to the underlying ocular disease}

Some of the complications after intravitreal injection of anti-VEGFs are similar among the different agents. This category of adverse events may be seen after any intravitreal anti-VEGF injection and is not affected by the underlying disease.
${ }^{1}$ Department of Ophthalmology, Eye Research Center, Rassoul Akram Hospital, Tehran University of Medical Sciences, Tehran, Iran

${ }^{2}$ Stanley M Truhlsen Eye Institute, University of Nebraska Medical Center, Omaha, Nebraska, USA

Correspondence: KG Falavarjani, Department of Ophthalmology, Eye Research Center, Rassoul Akram Hospital, Tehran University of Medical Sciences, SattarkhanNiayesh Street, Tehran 14456-13131, Iran. Tel: +98 912172 5850; Fax: +98 216650 9162; E-mail: drghasemi@ yahoo.com

Received: 16 January 2013 Accepted in revised form: 23 April 2013 Published online: 31 May 2013 
Endophthalmitis Infectious endophthalmitis remains one of the most devastating complications of intravitreal injections. In multicenter clinical trials with anti-VEGF therapy the incidence of endophthalmitis per patient has been reported to range from 0.019 to $1.6 \% .{ }^{10,11}$ However, the reported rate in the recent studies tends to be lower than that in early trials. ${ }^{10-16}$ The rate of endophthalmitis seems to be the same among different anti-VEGF agents $^{12}$ different injection settings, ${ }^{15}$ and different geographical locations. ${ }^{17}$

Recent studies reported that endophthalmitis caused by Streptococcus species was significantly more frequent after intravitreal injection than after intraocular surgery. ${ }^{10}$ Considering the fact that Streptococcus species comprise at least $41 \%$ culturable adult salivary flora, the difference in causative organisms in these two settings has been attributed to the contamination of injection field by aerosolization or droplet spread. ${ }^{10}$

The most important factor in reducing the risk of endophthalmitis following intravitreal injection is attention to issues before, during, and after the injection. Following the recent outbreaks of post-intravitreal bevacizumab injection endophthalmitis, special attention has been focused on aseptic preparation of the bevacizumab syringes. ${ }^{18}$ Noncompliance with recognized standards and poor aseptic technique from the compounding pharmacies were accounted responsible for these outbreaks, and strict adherence to the US Pharmacopeia Chapter 797 requirements was strongly recommended. ${ }^{19}$ Active external infection, including significant blepharitis, should be treated before injection. In addition, eyelid abnormalities such as ectropion are reported as risk factors for endophthalmitis and should be considered. ${ }^{11}$ The use of $5 \%$ povidoneiodine in the conjunctival fornices is an accepted universal practice and is a strong recommendation for preventing endophthalmitis. ${ }^{20}$ Topical antibiotics have been demonstrated to significantly reduce ocular surface bacteria, but have not been proven to have a significant impact on reducing the risk of endophthalmitis. ${ }^{11}$ During the injection procedure, the use of a sterile lid speculum is recommended to avoid needle contact with lids and lashes. The use of a sterile drape is optional but gloves, part of universal precautions, are appropriate. ${ }^{11}$ Recent studies emphasize the use of face mask and avoidance of talking on the reduction of bacterial contamination. ${ }^{21,22}$ Those performing intraocular injections should consider taking precautions against droplet contamination, such as not talking, talking with the mouth turned away from the field, or wearing a mask, especially if experiencing an upper respiratory infection, during intravitreal injection procedures. ${ }^{10}$ The use of postoperative antibiotics is controversial. Although most of the US retina specialists prefer to use post-injection topical antibiotics, recent studies report a significant increase in the antibiotic resistance of the isolated specimens from ocular flora and a greater rate of endophthalmitis with the use of topical antibiotics. ${ }^{17,23,24}$

Considering the often devastating outcome of endophthalmitis after intravitreal injections, and the importance of immediate treatment, the surgeons should instruct all patients to return at the first sign of any visual disturbance, or ocular pain.

Intraocular inflammation Intraocular inflammation is one of the main ocular adverse events associated with intraocular anti-VEGF pharmacologic agents. In the large clinical trials of intravitreal injection of ranibizumab for AMD, the rates of significant ocular inflammation were $1.4-2.9 \% .^{25}$ The reported rate after bevacizumab injection is lower (0.09-0.4); however, several lot-specific severe ocular inflammatory events were reported. ${ }^{25}$

It may be difficult to differentiate sterile intraocular inflammation from infectious endophthalmitis. In one study the time of presentation, presence of pain, and the severity of clinical findings were helpful. ${ }^{26}$ The symptoms began at an average of 2.55 days (range, 1-6 days) after injection in the endophthalmitis group and less than 1 day in the acute intraocular inflammation group. Seven of nine patients with endophthalmitis and two of five patients with acute intraocular inflammation had a painful eye on presentation. The anterior chamber reaction was severe in all endophthalmitis cases with seven of them presenting with at least one of the following: keratic precipitates, hypopyon, fibrin, or anterior synechia. None of these conditions was present in five acute intraocular inflammation cases. Other studies, however, could not find the presence or absence of pain, vitritis, decreased vision, or hypopyon, and the interval between injection and presentation helpful to distinguish culture-positive from culture-negative cases. ${ }^{27,28}$ Intraocular inflammation has also been reported with intravitreal aflibercept. In a letter sent to the US Food and Drug Administration dated 13 February 2012, Regeneron Pharmaceuticals (Tarrytown, NY, USA), the manufacturer of aflibercept, reported that as of 9 February 2012, 30000 injections of aflibercept have been performed in the US. During that period, 14 cases of adverse events consistent with sterile intraocular inflammation (an approximate rate of $0.05 \%$ per injection), following the use of aflibercept, have been reported to Regeneron Pharmaceuticals (http:/ / investor.regeneron.com/secfiling.cfm?filingID=120677412-566\&CIK=872589, last accessed 18 September 2012).

Although the presentation of symptoms in endophthalmitis may be more severe than in acute intraocular inflammation, the surgeons should consider 
every case of uveitis after intravitreal anti-VEGF injection as suspected endophthalmitis and should administer intravitreal antibiotics whenever there are high clinical suspicions. $^{26,27}$

Rhegmatogenous retinal detachment The overall incidence of rhegmatogenous retinal detachment (RRD) after intravitreal injection of anti-VEGF agents is low ( 0 to $0.67 \%) .{ }^{25,29}$ In a study on Medicare database, the differences in rates of RRD and retinal tear were not statistically significant between eyes with intravitreal anti-VEGF injection and a matched control group. ${ }^{25}$ The etiology of RRD after intravitreal injection have been proposed to be an induction of posterior vitreous detachment or an incorrect technique of injection. ${ }^{29}$ Paying attention to the surgical technique has been advocated to decrease the rate of RRD. This includes the precise site of injection $(3.5-4 \mathrm{~mm}$ posterior to the limbus), using smaller gauge needles, and tunnelled insertion of the needle for avoiding vitreous wick and reflux. ${ }^{29}$

Intraocular pressure elevation Acute rise of intraocular pressure (IOP) after intravitreal injection is injectionprocedure-related and lasts a few hours at most. ${ }^{30,31}$ Recent studies, however, have reported a significant number of intravitreal anti-VEGF injections is associated with an increased risk for IOP elevation. ${ }^{32,33}$ Patients with pre-existing glaucoma have higher rates of IOP elevation compared with those without pre-existing glaucoma. ${ }^{34}$ Several theories, including a pharmacologic effect of VEGF blockade, an inflammatory mechanism/ trabeculitis, impaired outflow owing to protein aggregates/silicone droplet debris, and damage to outflow pathways due to the repeated trauma and/or IOP spikes associated with the injection procedure, have been proposed for the possible cause of sustained IOP elevation after intravitreal anti-VEGF injections. ${ }^{33}$

As some eyes with IOP elevation after intravitreal antiVEGF injections need topical or surgical anti-glaucoma interventions, routine monitoring of IOP in all patients receiving intravitreal anti-VEGF therapy is recommended. ${ }^{32-34}$

Ocular hemorrhage There have been several reports of ocular hemorrhage following the use of intravitreal antiVEGF drugs. Subconjunctival hemorrhage has been reported to occur in nearly $10 \%$ of injections, with higher frequency in patients who were receiving aspirin. ${ }^{35}$ There has been a report of a massive choroidal detachment/ hemorrhage following intravitreal bevacizumab injection. ${ }^{36}$ Massive subretinal hemorrhage has been reported after ranibizumab and bevacizumab injections. ${ }^{37,38}$
In patients who were under treatment with anticoagulants, no new intraocular hemorrhages or other hemorrhagic complications were reported. ${ }^{39,40}$ Considering the increased risk of thromboembolic events after stopping anticoagulant therapy, discontinuation of the anticoagulants for intravitreal injections is not recommended. ${ }^{40}$

Systemic safety Anti-VEGF agents are used widely in treatment protocols of many solid cancers. Several adverse events have been reported with the systemic administration of anti-VEGF monoclonal antibodies, including thromboembolic events, myocardial infarction, stroke, hypertension, gastrointestinal perforations, and kidney disease. ${ }^{25,41-43}$ As all of the intravitreal anti-VEGF agents have been reported to be associated with detectable levels in the systemic circulation that may significantly suppress systemic VEGF levels, there is a scientific rationale for the occurrence of potential systemic adverse events. ${ }^{43}$

Large-scale clinical trials have demonstrated that pegaptanib has an excellent safety profile, with no systemic adverse effects attributable to VEGF inhibition. ${ }^{25}$ Although the primary ranibizumab trials individually did not show a significant increase in systemic risks and the overall incidence of systemic adverse events was low, other studies suggest a potential increase in rates of systemic diseases associated with ranibizumab injection, especially in elderly patients. ${ }^{44-46}$ Intraocular injection of ranibizumab was linked to a significant increase in nonocular hemorrhagic events, including ecchymosis, gastrointestinal hemorrhages, hematoma, vaginal hemorrhages, and subdural hematomas. ${ }^{25,46}$ The rates of any cause of deaths, myocardial infarctions, and cerebrovascular events were not significantly increased. ${ }^{46}$ Considering the limited details concerning the systemic adverse events associated with intravitreal bevacizumab reported within the articles, the data regarding the systemic safety of intravitreal bevacizumab are less conclusive. In comparison with the ranibizumab clinical trials, intravitreal bevacizumab injections may or may not be associated with an increased risk of nonocular hemorrhage. ${ }^{47}$ In a retrospective study of 1173 patients receiving bevacizumab injections, the reported systemic events included acute blood pressure elevations (0.59\%), cerebrovascular accidents $(0.5 \%)$, myocardial infarctions $(0.4 \%)$, iliac artery aneurysms $(0.17 \%)$, and five deaths. ${ }^{48}$ Different results were reported in the recent head-tohead trials and meta-analyses comparing intravitreal injections of bevacizumab and ranibizumab. Analysis of the Medicare claims database indicated an 11\% higher risk in all-cause mortality and 57\% higher risk of hemorrhagic stroke with bevacizumab, with no 
statistically significant differences among the risks of either myocardial infarction or ischemic stroke. ${ }^{49}$ A recent meta-analyses reported higher proportion of patients with serious systemic infections and gastrointestinal disorders with bevacizumab than with ranibizumab $(\mathrm{RR}=1.3 ; 95 \% \mathrm{CI} 1.0-1.7)$; the arterial thromboembolic events were similar between the two groups. ${ }^{47}$ Contrary to these studies, other reports could not find significant differences between ranibizumab and bevacizumab safety profile. Van der Reis et a ${ }^{50}$ systematically assessed and compared the incidences of adverse effects of ranibizumab, bevacizumab, and pegaptanib, and concluded that there is no sufficient evidence to show a difference between the safety profiles of different VEGF inhibitors. The Royal College of Ophthalmologists, United Kingdom, also stated that both drugs have a similar safety profile. ${ }^{51}$

Rare ocular and systemic side effects There are few reports of ocular and systemic adverse events associated with intravitreal anti-VEGF agents. Rare ocular adverse events include anterior ischemic optic neuropathy after bevacizumab injection, ${ }^{52,53}$ retinal venous occlusions after bevacizumab injection, ${ }^{54}$ retinal artery occlusions, ${ }^{55}$ hemorrhagic macular infarction, ${ }^{56}$ development or exacerbation of ocular ischemic syndrome, ${ }^{57}$ and sixth nerve palsy following bevacizumab injection. ${ }^{58}$ Rare systemic events include formed visual hallucinations, ${ }^{59}$ erectile dysfunction, ${ }^{60}$ and acute decrease in kidney function. ${ }^{61}$ The causative role of anti-VEGF agents in these cases remains to be established.

\section{Adverse events following intravitreal anti-VEGF injections: considerations in specific diseases}

Diabetic retinopathy and retinal vascular occlusions Several studies have shown the efficacy of intravitreal anti-VEGF injections in patients with diabetic macular edema, neovascular complications of diabetic retinopathy, diabetic vitrectomy, and retinal vascular occluions. $^{2-4,8,9,62}$

There are several reports of development or progression of tractional retinal detachment (TRD) after intravitreal injection of bevacizumab before vitrectomy for advanced proliferative diabetic retinopathy (PDR). ${ }^{63-65}$ In a retrospective series, 5.2\% of eyes developed or had progression of TRD following injection. Time from injection to TRD was a mean of 13 days (range 3-31 days), and 9 out of 11 (81.8\%) TRDs developed or progressed at 5 days or more after the injection. ${ }^{63}$ Although no definitive interval between the injection and vitrectomy surgery was defined, some authors suggest that shorter interval is safer. ${ }^{63,66}$ This should also be considered in eyes with active PDR with extensive new vessels at risk for progression of TRD that might involve the fovea. The risk factors for the development and progression of TRD were suggested to be more than 15 years from the onset of the diabetes mellitus, more than 13 days from the injection, and the use of higher doses of bevacizumab $(2.5 \mathrm{mg}) .{ }^{67}$ Intravitreal injection of anti-VEGF agents should be used with extreme caution in extensive neovascularization secondary to diabetic retinopathy or RVO, and the patient should be followed closely for the possible need for vitrectomy.

Ghost cell glaucoma has been reported following the use of bevacizumab as an adjunct to vitrectomy for PDR. ${ }^{68}$

There are reports of decrease in retrobulbar blood flow parameters, retinal arteriolar vasoconstriction, and worsening of macular ischemia after intravitreal injection of anti-VEGF agents. ${ }^{69-71}$ Although the clinical

consequences of these effects are not known, it has been recommended that prolonged anti-VEGF therapy in eyes with significant macular ischemia should be monitored by repeated fluorescein measurements. ${ }^{71}$

Age-related macular degeneration Retinal pigment epithelium (RPE) tears may occur spontaneously or after therapeutic intervention in patients with AMD. Several recent publications have reported RPE tears associated with the use of intravitreal anti-VEGFs in choroidal neovascularization associated with AMD. ${ }^{72-74}$ The reported incidence of RPE tear after anti-VEGF therapy varies from 0.06 to $27 \%$ and seems to be higher than the incidence in the natural course of the disease. $^{75}$

Pre-existing RPE detachment (PED) or fibrovascular PED is considered the major risk factor for RPE tear. ${ }^{75}$ Large PED diameter and vertical height on optical coherence tomography have been shown to be predictive of RPE tear. ${ }^{76}$ In a recent study on three major AMD trials, no statistically significant differences were observed in the incidence of RPE tears within a 2-year treatment period in patients who received ranibizumab versus control treatment. ${ }^{77}$ In patients with RPE tears, better visual acuity outcomes were observed in those treated with anti-VEGF agents. ${ }^{75,77}$

Other retinal diseases Several studies reported successful use of bevacizumab in the eyes with severe ROP. 5,78 However, caution is necessary when bevacizumab is used in advanced stages of ROP. Similar to what happens in PDR, the fibrotic component of neovascularization may accelerate after inhibition of angiogenesis and the retinal detachment might worsen. ${ }^{79}$ The surgeon should be ready for vitrectomy within 1 week after intravitreal injection of bevacizumab in eyes with ROP stage 
4 and $5 .{ }^{80}$ Late recurrence of ROP and TRD may occur 4-35 weeks after initial regression with intravitreal bevacizumab and long-term follow-up of these patients is warranted. ${ }^{81,82}$

There are several reports of successful treatment of Coats' disease with intravitreal bevacizumab alone or in combination with other treatment modalities. ${ }^{83-85}$ However, the patients treated with intravitreal bevacizumab are at risk for vitreoretinal fibrosis and TRD despite resolution of the retinopathy. ${ }^{85}$

Intraocular injection of bevacizumab has been reported to cause rapid regression of anterior segment neovascularization in the eyes with neovascular glaucoma. ${ }^{4,86}$ In the subset of patients that neovascular glaucoma was secondary to ocular ischemic syndrome, intraocular injection of bevacizumab may lead to central retinal artery occlusion. ${ }^{86}$

Intravitreal bevacizumab injections may be associated with the development of secondary RRD in patients of Eales' disease within 7 days of injection. ${ }^{87}$

\section{Conclusions}

Anti-VEGF therapy is the mainstay for the treatment of many retinal diseases. Despite its promising efficacy in halting the disease and improving the vision for the patients, intravitreal injection of anti-VEGF agents may be associated with devastating complications. Ophthalmologists who employ anti-VEGF agents for their patients should consider the potential systemic and ocular risks and benefits of intravitreal anti-VEGF therapy and closely monitor the patients for adverse effects that may occur in the immediate or subsequent periods after administration of the drugs.

\section{Conflict of interest}

The University of Nebraska Medical Center, the employer of QDN, has received research funding from Genentech, Inc., Regeneron, Inc., and Abbott, Inc,. QDN has served on the Steering Committee for clinical trials sponsored by Genentech, Inc. and Regeneron, Inc. QDN has served on the Scientific Advisory Boards for Santen, Inc. and Bausch and Lomb, Inc. KGF has no conflict of interest.

\section{References}

1 Wong TY, Liew G, Mitchell P. Clinical update: new treatments for age-related macular degeneration. Lancet 2007; 370(9583): 204-206.

2 Nicholson BP, Schachat AP. A review of clinical trials of anti-VEGF agents for diabetic retinopathy. Graefes Arch Clin Exp Ophthalmol 2010; 248(7): 915-930.
3 Wong TY, Scott IU. Clinical practice. Retinal-vein occlusion. N Engl J Med 2010; 363(22): 2135-2144.

4 Falavarjani KG, Modarres M, Nazari H. Therapeutic effect of bevacizumab injected into the silicone oil in eyes with neovascular glaucoma after vitrectomy for advanced diabetic retinopathy. Eye 2010; 24: 717-719.

5 Nazari H, Parvaresh MM, Modarres M, Falavarjani KG. Intravitreal bevacizumab in combination with laser therapy for the treatment of severe retinopathy of prematurity (ROP) associated with vitreous or retinal hemorrhage. Graefes Arch Clin Exp Ophthalmol 2010; 248: 1713-1718.

6 Detorakis ET, Agorogiannis G, Drakonaki EE, Tsilimbaris MK, Pallikaris IG. Successful management of choroidal metastasis with intravitreal ranibizumab injection. Ophthalmic Surg Lasers Imaging 2012; 43: e47-e51.

7 Ip MS, Scott IU, Brown GC, Brown MM, Ho AC, Huang SS et al. Antivascular endothelial growth factor pharmacotherapy for age-related macular degeneration: a report by the American Academy of Ophthalmology. Ophthalmology 2008; 115: 1837-1846.

8 Campochiaro PA, Heier JS, Feiner L, Gray S, Saroj N, Rundle AC et al. Ranibizumab for macular edema following branch retinal vein occlusion: six-month primary end point results of a phase III study. Ophthalmology 2010; 117: 1102-1112.

9 Nguyen QD, Brown DM, Marcus DM, Boyer DS, Patel S, Feiner $L$ et al. Ranibizumab for diabetic macular edema: results from 2 phase III randomized trials: RISE and RDE. Ophthalmology 2012; 119: 789-801.

10 McCannel CA. Meta-analysis of endophthalmitis after intravitreal injection of anti-vascular endothelial growth factor agents. Retina 2011; 31: 654-661.

11 Scott IU, Flynn Jr, HW. Reducing the risk of endophthalmitis following intravitreal injections. Retina 2007; 27: 10-12.

12 Fintak DR, Shah GK, Kj Blinder, Regillo CD, Pollack J, Heier JS et al. Incidence of endophthalmitis related to intravitreal injection of bevacizumab and ranibizumab. Retina 2008; 28: 1395-1399.

13 Diago T, McCannel CA, Bakri SJ, Pulido JS, Edwards AO, Pach JM. Infectious endophthalmitis after intravitreal injection of antiangiogenic agents. Retina 2009; 29: 601-605.

14 Mason 3rd, JO, White MF, Feist RM, Thomley ML, Albert MA, Persaud TO et al. Incidence of acute onset endophthalmitis following intravitreal bevacizumab (Avastin) injection. Retina 2008; 28(4): 564-567.

15 Pilli S, Kotsolis A, Spaide RF, Slakter J, Freund KB, Sorenson $\mathrm{J}$ et al. Endophthalmitis associated with intravitreal anti-vascular endothelial growth factor therapy injections in an office setting. Am J Ophthalmol 2008; 145(5): 879-882.

16 Moshfeghi AA, Rosenfeld PJ, Flynn Jr, HW, Schwartz SG, Davis JL, Murray TG et al. Endophthalmitis after intravitreal anti-vascular endothelial growth antagonists. Retina 2011; 31: 662-668.

17 Falavarjani KG, Modarres M, Hashemi M, Parvaresh MM, Naseripour M, Zare-Moghaddam A et al. Incidence of acute endophthalmitis after intravitreal bevacizumab injection in a single clinical center. Retina 2013; 33(5): 971-974.

18 Goldberg RA, Flynn HW, Isom RF, Miller D, Gonzalez S. An outbreak of streptococcus endophthalmitis after intravitreal injection of bevacizumab. Am J Ophthalmol 2012; 153(2): 204-208. 
19 Gonzalez S, Rosenfeld PJ, Stewart MW, Brown J, Murphy SP. Avastin doesn't blind people, people blind people. Am J Ophthalmol 2012; 153(2): 196-203.

$20 \mathrm{Yu}$ CQ, Ta CN. Prevention of postcataract endophthalmitis: evidence-based medicine. Curr Opin Ophthalmol 2012; 23(1): 19-25.

21 Doshi RR, Leng T, Fung AE. Reducing oral flora contamination of intravitreal injections with face mask or silence. Retina 2012; 32(3): 473-476.

22 Wen JC, McCannel CA, Mochon AB, Garner OB. Bacterial dispersal associated with speech in the setting of intravitreous injections. Arch Ophthalmol 2011; 129(12): 1551-1554.

23 Green-Simms AE, Ekdawi NS, Bakri SJ. Survey of intravitreal injection techniques among retinal specialists in the United States. Am J Ophthalmol 2011; 151(2): 329-332.

24 Milder E, Vander J, Shah C, Garg S. Changes in antibiotic resistance patterns of conjunctival flora due to repeated use of topical antibiotics after intravitreal injection. Ophthalmology 2012; 119(7): 1420-1424.

25 Tolentino M. Systemic and ocular safety of intravitreal anti-VEGF therapies for ocular neovascular disease. Surv Ophthalmol 2011; 56: 95-113.

26 Mezad-Koursh D, Goldstein M, Heilwail G, Zayit-Soudry S, Loewenstein A, Barak A. Clinical characteristics of endophthalmitis after an injection of intravitreal antivascular endothelial growth factor. Retina 2010; 30: 1051-1057.

27 Shah CP, Garg SJ, Vander JF, Brown GC, Kaiser RS, Haller JA. Post-Injection Endophthalmitis (PIE) Study Team. Outcomes and risk factors associated with endophthalmitis after intravitreal injection of anti-vascular endothelial growth factor agents. Ophthalmology 2011; 118: 2028-2034.

28 Irigoyen C, Ziahosseini K, Morphis G, Stappler T, Heimann H. Endophthalmitis following intravitreal injections. Graefes Arch Clin Exp Ophthalmol 2012; 250(4): 499-505.

29 Meyer CH, Michels S, Rodrigues EB, Hager A, Mennel S, Schmidt JC et al. Incidence of rhegmatogenous retinal detachments after intravitreal antivascular endothelial factor injections. Acta Ophthalmol 2011; 89: 70-75.

30 Bakri SJ, Pulido JS, McCannel CA, Hodge DO, Diehl N, Hillemeier J. Immediate intraocular pressure changes following intravitreal injections of triamcinolone, pegaptanib, and bevacizumab. Eye 2009; 23(1): 181-185.

31 Gismondi M, Salati C, Salvetat ML, Zeppieri M, Brusini P. Short-term effect of intravitreal injection of Ranibizumab (Lucentis) on intraocular pressure. J Glaucoma 2009; 18(9): 658-661.

32 Kahook MY, Kimura AE, Wong LJ, Ammar DA, Maycotte MA, Mandava N. Sustained elevation in intraocular pressure associated with intravitreal bevacizumab injections. Ophthalmic Surg Lasers Imaging 2009; 40: 293-295.

33 Hoang QV, Mendonca LS, Della Torre KE, Jung JJ, Tsuang $\mathrm{AJ}$, Freund KB. Effect on intraocular pressure in patients receiving unilateral intravitreal anti-vascular endothelial growth factor injections. Ophthalmology 2012; 119: 321-326.

34 Good TJ, Kimura AE, Mandava N, Kahook MY. Sustained elevation of intraocular pressure after intravitreal injections of anti-VEGF agents. Br J Ophthalmol 2011; 95: 1111-1114.

35 Ladas ID, Karagiannis DA, Rouvas AA, Kotsolis AI, Liotsou A, Vergados I. Safety of repeat intravitreal injections of bevacizumab versus ranibizumab: our experience after 2,000 injections. Retina 2009; 29(3): 313-318.
36 Brouzas D, Koutsandrea C, Moschos M, Papadimitriou S, Ladas I, Apostolopoulos M. Massive choroidal hemorrhage after intravitreal administration of bevacizumab (Avastin) for AMD followed by contralateral sympathetic ophthalmia. Clin Ophthalmol 2009; 3: 457-459.

37 Karagiannis DA, Mitropoulos P, Ladas ID. Large subretinal haemorrhage following change from intravitreal bevacizumab to ranibizumab. Ophthalmologica 2009; 223(4): 279-282.

38 Modarres M, Naseripour M, Falavarjani KG, Nikeghbali A, Hashemi M, Parvaresh MM. Intravitreal injection of $2.5 \mathrm{mg}$ vs $1.25 \mathrm{mg}$ bevacizumab (avastin) for treatment of CNV associated with AMD. Retina 2009; 29: 319-324.

39 Loukopoulos V, Meier C, Gerding H. Hemorrhagic complications after intravitreal injections of ranibizumab in patients under coumarin-type anticoagulation. Klin Monbl Augenheilkd 2010; 227(4): 289-291.

40 Mason 3rd JO, Frederick PA, Neimkin MG, White Jr MF, Feist RM, Thomley ML et al. Incidence of hemorrhagic complications after intravitreal bevacizumab (avastin) or ranibizumab (lucentis) injections on systemically anticoagulated patients. Retina 2010; 30(9): 1386-1389.

41 Gordon MS, Cunningham D. Managing patients treated with bevacizumab combination therapy. Oncology 2005; 69(Suppl 3): 25-33.

42 Scappaticci FA, Skillings JR, Holden SN, Gerber HP, Miller $\mathrm{K}$, Kabbinavar $\mathrm{F}$ et al. Arterial thromboembolic events in patients with metastatic carcinoma treated with chemotherapy and bevacizumab. J Natl Cancer Inst 2007; 99: 1232-1239.

43 Csaky K, Do DV. Safety implications of vascular endothelial growth factor blockade for subjects receiving intravitreal anti-vascular endothelial growth factor therapies. Am J Ophthalmol 2009; 148: 647-656.

44 Schmidt-Erfurth U. Clinical safety of ranibizumab in agerelated macular degeneration. Expert Opin Drug Saf 2010; 9(1): 149-165.

45 Lim LS, Cheung CG, Mitchell P, Wong TY. Emerging evidence concerning systemic safety of anti-VEGF agents - should ophthalmologists be concerned? Am J Ophthalmol 2011; 152: 329-331.

46 Schmucker C, Loke YK, Ehlken C, Agostini HT, Hansen LL, Antes $\mathrm{G}$ et al. Intravitreal bevacizumab (Avastin) versus ranibizumab (Lucentis) for the treatment of age-related macular degeneration: a safety review. Br J Ophthalmol 2011; 95(3): 308-317.

47 Schmucker C, Ehlken C, Agostini HT, Antes G, Ruecker G, Lelgemann $\mathrm{M}$ et al. A safety review and meta-analyses of bevacizumab and ranibizumab: off-label versus goldstandard. PLoS One 2012; 7(8): e42701.

$48 \mathrm{Wu}$ L, Martinez-Castellanos MA, Quiroz-Mercado H, Arevalo JF, Berrocal MH, Farah ME et al. Twelve-month safety of intravitreal injections of bevacizumab (Avastin): results of the Pan-American Collaborative Retina Study Group (PACORES). Graefes Arch Clin Exp Ophthalmol 2008; 246(1): 81-87.

49 Gower EW, Cassard S, Chu L, Varma R, Klein R. Adverse event rates following intravitreal injection of avastin or lucentis for treating age-related macular degeneration. ARVO Meet Abstr 2011; 52: 6644.

50 van der Reis MI, La Heij EC, De Jong-Hesse Y, Ringens PJ, Hendrikse F, Schouten JS. A systematic review of the adverse events of intravitreal anti-vascular endothelial growth factor injections. Retina 2001; 31: 1449-1469. 
51 The Royal College of Ophthalmologists. Statement. Bevacizumab (Avastin) Use in Medical Ophthalmology 2011. Available at : http://www.rcophth.ac.uk/news.asp? itemid $=647$ \&itemTitle $=$ RCOphth + Review + concludes + that + Avastin + and + Lucentis + are + equally + effec tive + in + treating + wet + AMD\&section $=24 \&$ section Title=News. Accessed 02 April 2012.

52 Ganssauge M, Wilhelm H, Bartz-Schmidt KU, Aisenbrey S. Nonarteritic anterior ischemic optic neuropathy (NA-AION) after intravitreal injection of bevacizumab (Avastin) for treatment of angoid streaks in pseudoxanthoma elasticum. Graefes Arch Clin Exp Ophthalmol 2009; 247(12): 1707-1710.

53 Hosseini H, Razeghinejad MR. Anterior ischemic optic neuropathy after intravitreal injection of bevacizumab. J Neuroophthalmol 2009; 29(2): 160-161.

54 Mansour AM, Bynoe LA, Welch JC, Pesavento R, Mahendradas $\mathrm{P}$, Ziemssen $\mathrm{F}$ et al. Retinal vascular events after intravitreal bevacizumab. Acta Ophthalmol 2010; 88(7): 730-735.

55 von Hanno T, Kinge B, Fossen K. Retinal artery occlusion following intravitreal anti-VEGF therapy. Acta Ophthal 2010; 88(2): 263-266.

56 Furino C, Boscia F, Cardascia N, Alessio G, Sborgia C. Hemorrhagic macular infarction after intravitreal bevacizumab for central retinal vein occlusion. Ophthalmic Surg Lasers Imaging 2010; e-pub ahead of print 9 March 2010; doi:10.3928/15428877-20100215-57.

57 Huang ZL, Lin KH, Lee YC, Sheu MM, Tsai RK. Acute vision loss after intravitreal injection of bevacizumab (avastin) associated with ocular ischemic syndrome. Ophthalmologica 2010; 224(2): 86-89.

58 Cakmak HB, Toklu Y, Yorgun MA, Simşek S. Isolated sixth nerve palsy after intravitreal bevacizumab injection. Strabismus 2010; 18(1): 18-20.

59 Meyer $\mathrm{CH}$, Mennel S, Hörle S, Schmidt JC. Visual hallucinations after intravitreal injection of bevacizumab in vascular agerelated macular degeneration. Am J Ophthalmol 2007; 143(1): 169-170.

60 Yohendran J, Chauhan D. Erectile dysfunction following intravitreal bevacizumab. Middle East Afr J Ophthalmol 2010; 17(3): 281-284.

61 Pellé G, Shweke N, Duong Van Huyen JP, Tricot L, Hessaïne $\mathrm{S}$, Frémeaux-Bacchi $\mathrm{V}$ et al. Systemic and kidney toxicity of intraocular administration of vascular endothelial growth factor inhibitors. Am J Kidney Dis 2011; 57(5): 756-759.

62 Falavarjani KG, Modarres M. Perioperative use of bevacizumab in vitrectomy for proliferative diabetic retinopathy: a literature review. Iranian J Ophthalmol 2010; 22(4): 5-12.

63 Arevalo JF, Maia M, Flynn Jr HW, Saravia M, Avery RL, $\mathrm{Wu} \mathrm{L}$ et al. Tractional retinal detachment following intravitreal bevacizumab (Avastin) in patients with severe proliferative diabetic retinopathy. Br J Ophthalmol 2008; 92(2): 213-216.

64 Oshima Y, Shima C, Wakabayashi T, Kusaka S, Shiraga F, Ohji $\mathrm{M}$ et al. Microincision vitrectomy surgery and intravitreal bevacizumab as a surgical adjunct to treat diabetic traction retinal detachment. Ophthalmology 2009; 116(5): 927-938.

65 Yeh PT, Yang CM, Lin YC, Chen MS, Yang CH. Bevacizumab pretreatment in vitrectomy with silicone oil for severe diabetic retinopathy. Retina 2009; 29(6): 768-774.
66 Modarres M, Nazari H, Falavarjani KG, Naseripour M, Hashemi M, Parvaresh MM. Intravitreal injection of bevacizumab before vitrectomy for proliferative diabetic retinopathy. Eur J Ophthalmol 2009; 19(5): 848-852.

67 Arevalo JF, Sanchez JG, Laave AF, Wu L, Maia M, Bonafonte $\mathrm{S}$ et al. Intravitreal bevacizumab (avastin) for diabetic retinopathy: The 2010 GLADAOF lecture. J Ophthalmol 2011; 2011: 584238.

68 Liu L, Wu WC, Yeung L, Wang NK, Kuo YH, Chao AN et al. Ghost cell glaucoma after intravitreal bevacizumab for postoperative vitreous hemorrhage following vitrectomy for proliferative diabetic retinopathy. Ophthalmic Surg Lasers Imaging 2010; 41(1): 72-77.

69 Mete A, Saygili O, Mete A, Bayram M, Bekir N. Effects of intravitreal bevacizumab (Avastin) therapy on retrobulbar blood flow parameters in patients with neovascular age-related macular degeneration. J Clin Ultrasound 2010; 38(2): 66-70.

70 Papadopoulou DN, Mendrinos E, Mangioris G, Donati G, Pournaras CJ. Intravitreal ranibizumab may induce retinal arteriolar vasoconstriction in patients with neovascular age-related macular degeneration. Ophthalmology 2009; 116(9): 1755-1761.

71 Manousaridis K, Talks J. Macular ischemia: a contraindication for anti-VEGF treatment in retinal vascular disease? Br J Ophthalmol 2012; 96: 179-184

72 Chang LK, Flaxel CJ, Lauer AK, Sarraf D. RPE tears after pegaptanib treatment in age-related macular degeneration. Retina 2007; 27: 857-863.

73 Smith BT, Kraus CL, Apte RS. Retinal pigment epithelial tears in ranibizumab-treated eyes. Retina 2009; 29: 335-339.

74 Shaikh S, Olson JC, Richmond PP. Retinal pigment epithelial tears after intravitreal bevacizumab injection for exudative age-related macular degeneration. Indian J Ophthalmol 2007; 55: $470-472$.

75 Chang LK, Sarraf D. Tears of the retinal pigment epithelium: an old problem in a new era. Retina 2007; 27(5): 523-534.

76 Chiang A, Chang LK, Yu F, Sarraf D. Predictors of anti-VEGF-associated retinal pigment epithelial tear using FA and OCT analysis. Retina 2008; 28(9): 1265-1269.

77 Cunningham Jr, ET, Feiner L, Chung C, Tuomi L, Ehrlich JS. Incidence of retinal pigment epithelial tears after intravitreal ranibizumab injection for neovascular age-related macular degeneration. Ophthalmology 2011; 118(12): 2447-2452.

78 Quiroz-Mercado H, Martinez-Castellanos MA, Hernandez- Rojas ML, Salazar-Teran N, Chan RV. Antiangiogenic therapy with intravitreal bevacizumab for retinopathy of prematurity. Retina 2008; 28(Suppl): S19-S25.

79 Honda S, Hirabayashi H, Tsukahara Y, Negi A. Acute contraction of the proliferative membrane after an intravitreal injection of bevacizumab for advanced retinopathy of prematurity. Graefes Arch Clin Exp Ophthalmol 2008; 246: 1061-1063.

80 Wu WC, Yeh PT, Chen SN, Yang CM, Lai CC, Kuo HK. Effects and complications of bevacizumab use in patients with retinopathy of prematurity: a multicenter study in Taiwan. Ophthalmology 2011; 118: 176-183.

81 Lee BJ, Kim JH, Heo H, Yu YS. Delayed onset atypical vitreoretinal traction band formation after an intravitreal injection of bevacizumab in stage 3 retinopathy of prematurity. Eye (Lond) 2012; 26: 903-910.

$82 \mathrm{Hu}$ J, Blair MP, Shapiro MJ, Lichtenstein SJ, Galasso JM, Kapur R. Reactivation of retinopathy of prematurity after bevacizumab injection. Arch Ophthalmol 2012; 130(8): 1000-1006. 
83 Goel N, Kumar V, Seth A, Raina UK, Ghosh B. Role of intravitreal bevacizumab in adult onset Coats disease. Int Ophthalmol 2011; 31: 183-190.

84 Bohm MR, Uhlig CE. Use of intravitreal triamcinolone and bevacizumab in Coats' disease with central macular edema. Graefes Arch Clin Exp Ophthalmol 2011; 249: 1099-1101.

85 Ramasubramanian A, Shields CL. Bevacizumab for Coats' disease with exudative retinal detachment and risk of vitreoretinal traction. Br J Ophthalmol 2012; 96: 356-359.
86 Higashide T, Murotani E, Saito Y, Ohkubo S, Sugiyama K. Adverse events associated with intraocular injections of bevacizumab in eyes with neovascular glaucoma. Graefes Arch Clin Exp Ophthalmol 2012; 250(4): 603-610.

87 Kumar A, Sehra SV, Thirumalesh MB, Gogia V. Secondary rhegmatogenous retinal detachment following intravitreal bevacizumab in patients with vitreous hemorrhage or tractional retinal detachment secondary to Eales' disease. Graefes Arch Clin Exp Ophthalmol 2012; 250: 685-690. 